Balod :Theoretical Determination of the formability of (AA5182 / Polypropylene/ ..

\title{
Theoretical Determination of the formability of (AA5182 / Polypropylene/ AA5182)sandwich sheets using different yield criterion
}

\author{
Anas Obied Balod \\ Mechanical Engineering Department, Mosul University, Mosul , Iraq
}

\begin{abstract}
The effect of anisotropic yield criteria is very efficient in theoretical determination of limits strain of forming limit diagram(FLD) for sheet metals. In this paper the forming limit diagrams for (AA5182/polypropylene/AA5182) [AA/PP/AA] sandwich sheets have been determined theoretically using Marciniak-Kuczynski analysis with different anisotropic yield functions (Hosford 1979 and Barlat \& lian 1989). It is shown that the determination of forming limit curve using (Barlat \& lian1989 criterion) with the (M-K) analysis, gave the best results compared with the other anisotropic yield criteria. Also the forming limit stress diagram is theoretically determined using Marciniak-Kuczynski analysis and (Hosford \& Barlat-lian) yield criterion for sandwich sheets and AA5182 skin sheet. It is shown that the limit stress in experimental and theoretical forming limit stress curve for AA5182 skin sheet is higher than the limit stress in sandwich sheets.
\end{abstract}

Keywords : Composite materials, forming limit diagram(FLD), forming limit stress diagram (FLSD), stretch forming, anisotropic yield criterion.

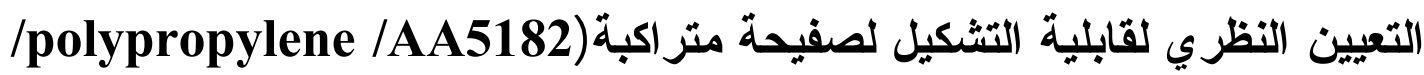 (AA5182 باستخدام نظريات خضوع مختلفة متركة.}

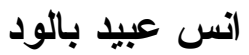 \\ قسم الهندسة الميكانيكية -جامعة الموصل /موصل -العراق
}

الخلاصة

أن تأثير نظريات الخضو عات كفاءة على التعيين النظري لحدود الانفعال في منحني حد التنكيل للصفائح المعدنية. في هذا

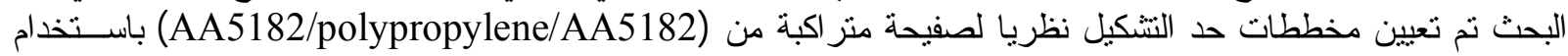

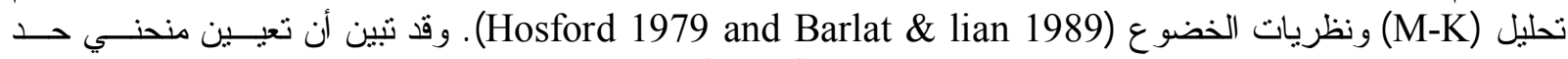

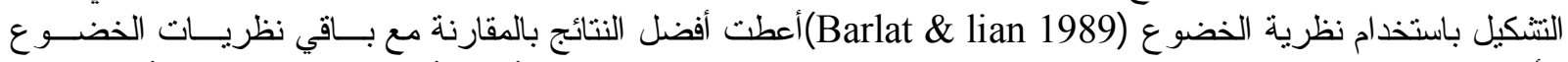



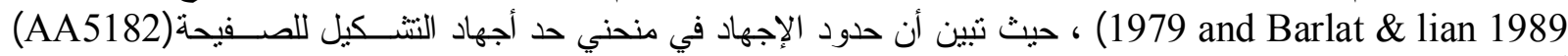
أعلى من الصفيحة المتر اكبة عمليا ونظريا. 


\section{$\begin{array}{llll}\text { Al-Rafidain Engineering } & \text { Vol.18 } & \text { No.2 } & \text { April } 2010\end{array}$}

Notation
\begin{tabular}{|c|l|c|}
\hline Symbol & Definition & Unit \\
\hline$\sigma 1, \sigma 2, \sigma 3$ & Principal stresses & $\mathrm{MPa}$ \\
\hline$\varepsilon 1 \varepsilon^{2} \varepsilon_{3}$ & Principal strains & \\
\hline $\mathrm{m}$ & Strain rate sensitivity & \\
\hline $\mathrm{n}$ & Strain hardening exponent & $\mathrm{MPa}$ \\
\hline$\sigma^{\prime}$ & effective stress & \\
\hline$\dot{\varepsilon}^{\prime}$ & effective strain & $1 / \mathrm{sec}$ \\
\hline$\varepsilon^{\prime}$ & strain rate & $1 / \mathrm{sec}$ \\
\hline$\varepsilon^{\prime \prime}$ & effective strain rate & \\
\hline$\rho$ & ratio of minor strain to major strain & \\
\hline ta & thickness of the sheet & \\
\hline $\mathrm{tb}$ & Thickness of groove & \\
\hline$\alpha$ & Principle stress ratio & \\
\hline$f$ & Imperfection factor & $\mathrm{MPa}$ \\
\hline $\mathrm{a}$ & Yield criterion index & \\
\hline $\mathrm{K}$ & Strength coefficient & \\
\hline $\mathrm{R}^{\prime}$ & Normal plastic anisotropic ratio & \\
\hline $\mathrm{R} 0$ & Plastic anisotropic ratio with rolling direction & \\
\hline $\mathrm{R} 90$ & $\begin{array}{l}\text { Plastic anisotropic ratio transverse to rolling } \\
\text { direction }\end{array}$ & \\
\hline$\varphi$ & ratio of principal stress to effective stress & \\
\hline$\beta$ & Ratio of effective strain to principal strain & \\
\hline $\mathrm{M}-\mathrm{K}$ & Marciniak-Kuczynski analysis & $\mathrm{N}$ \\
\hline $\mathrm{F} 1 \mathrm{a}$ & Principal Force in region (a) in M.K analysis & \\
\hline $\mathrm{F} 1 \mathrm{~b}$ & Principal Force in region (b) in M.K analysis & \\
\hline $\mathrm{A}, \mathrm{h}, \mathrm{c}$ & $\begin{array}{l}\text { Parameter using in Barlat-lian yield } \\
\text { criterion }\end{array}$ & \\
\hline
\end{tabular}

\section{Introduction:}

The sandwich sheets connect the advantages of miscellaneous materials (e.g. low density, high bend resistance, sound and vibration insulation, energy absorption, high load-capacity at a low weight) with each other. Nowadays these new materials and designs are appreciated as key technologies for innovative research and development. The further development of the materials, the optimization of material applications and the necessary manufacturing method with reduced costs and time are permanent research objectives[1].

Sheet metals exhibit a highly anisotropic material behavior by cold rolling. It is therefore of major importance to extend the plastic instability analysis to anisotropic materials. Constitutive relations for the plastic yielding and deformation of anisotropic metals at a macroscopic level were proposed long ago by (Hill 1948)[2] This theory was the simplest conceivable one for anisotropic materials, however, inevitable limitations of its range of validity have eventually become apparent. The original M-K analysis [3] was based on Hill's 1948 yield criterion [2]. However, it can be seen from the comparison with experiments and predicted results (Painter and Pearce 1974)[4] that this analysis overestimates the limit strains towards the equibiaxial 
Balod :Theoretical Determination of the formability of (AA5182 / Polypropylene/ ..

strain region, and underestimates the limit strains towards the plane strain region, particularly for materials with $\mathrm{R}$ values less than unity [such as aluminum or brass]. In addition, the calculated limit strains for the right hand side of the FLDs are very sensitive to the material anisotropy, a phenomenon that has not been observed in experiment. Sowerby and Duncan 1971[5] argued that the difference between these two stress states depends on the yield criterion and the shape of the corresponding yield locus. The effect of R on the FLDs depends on how the R-value affects the yield locus shape. Using (Hill's 1948) yield criterion, the stress ratios for positive strain ratios depend strongly on the value of R.

Hill's 1979 [6] yield criterion, taken with the assumption of the principle of equivalence of plastic work, was proposed to account for the so-called "anomalous behavior" of aluminum. This yield criterion has undergone criticism. One line of attack is represented by the work of (Parmar and Mellor 1978)[7].

Hosford 1979 [8] developed an extension of Hill's 1948 yield criterion, which is also found to be a special case of Hill's 1979 yield criterion. This criterion has been used by (Graf and Hosford 1990)[9] for sheet metals with normal anisotropy. Later, (Padwal and Chaturvedi 1992)[10] also used (Hosford's 1985)[11] planar anisotropy yield criterion to analyze the insatiable behavior of strain localization,they found that the effect of planar anisotropy is negligible while the predictions are strongly dependent on exponent "a" (exponent in yield criterion). Predictions with $a=5,6$ or 8 match the experimental results much better than the predictions that were obtained from Hill's yield criterion.

Friedman and Pan 2000 [12] studied the effect of different yield criteria (Hill 1948),(Hill 1979 ) and(Hosford 1979) on right hand side of the forming limit diagram.

Dariani B.M and Azodi H.D 2003[13] show the agreement between theoretical and experimental results by changing the index of Hill1979 yield criterion for right and left hand of FLD.

In recent years, metal-plastic laminates and sandwich sheets have been developed in order to considerably reduce the weight of vehicles and improve the sound-deadening properties of the materials. Among various sandwich sheets, aluminum /plastic /aluminum (Al/P/Al) sandwich sheets have generated a considerable interest as potential light-weight and sound-deadening sheets for the body panels of high performance vehicles. However, in order to apply $\mathrm{Al} / \mathrm{P} / \mathrm{Al}$ sandwich sheets for automotive body panels, many requirements have to be met such as the proper combination of strength, flexural rigidity and formability, dent and corrosion resistance, joinability, recyclability,etc[14]. In order to meet these stringent requirements for automotive body panels, AA5182/polypropylene /AA 5182 (AA/PP/AA) sandwich sheets have been developed in recent years. The AA/PP/AA sandwich sheet consists of two 5182 aluminum alloy (AA5182) skins with a thermoplastic polypropylene core in between in order to achieve the proper combination of the lightest weight per unit area, while meeting the flexural rigidity criterion.

Kim et-al2003 [15] studied the formability of sandwich sheets (AA/PP/AA) by determining the FLDs experimentally and comparing with the theoretical FLDs (using Hill1948,Barlat 2000).

The purpose of this paper is to determine which existing anisotropic yield criterion is better to represent the formability of the sandwich sheet AA/PP/AA using different anisotropic yield criterion (Hosford1979 and Barlat-lian), to compare with experimental and theoretical FLDs for $\operatorname{kim}(2003)[15]$, and to determine the limit stress on forming limit stress diagram for sandwich sheet and AA5182 skin sheet theoretically and experimentally. 


\section{Al-Rafidain Engineering $\quad$ Vol.18 $\quad$ No.2 $\quad$ April 2010}

\section{Chemical composition and mechanical property:}

The AA/PP/AA sandwich sheet with $1.2 \mathrm{~mm}$ thickness (1.2t) consists of two AA5182 aluminum skins and a thermoplastic polypropylene core, which are 0.2 and $0.8 \mathrm{~mm}$ in thickness, respectively, as shown in Fig. (1). The sandwich sheet has achieved about $65 \%$ weight saving and the formability was evaluated on the AA5182 skin and the AA/PP/AA sandwich sheet[15].

\begin{tabular}{|c|}
\hline AA5182 Skin \\
\hline Polypropylene core \\
\hline AA5182 Skin \\
\hline
\end{tabular}

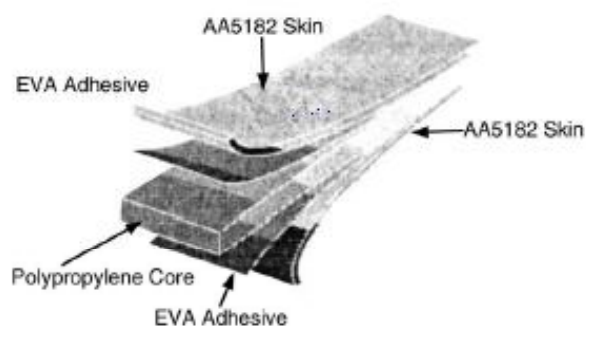

Fig.(1) Schematic view of the AA/PP/AA sandwich sheet

The chemical composition of the aluminum alloy AA5182 which was determined by kim etal [15] is shown in table(1).

Table(1) Chemical analysis of AA5182 skin sheet

\begin{tabular}{|c|c|r|r|r|r|r|r|r|}
\hline Material & $\mathrm{M} \%$ & $\mathrm{Mn} \%$ & $\mathrm{Fe} \%$ & $\mathrm{Si} \%$ & $\mathrm{Cu} \%$ & $\mathrm{Cr} \%$ & $\mathrm{Ti} \%$ & $\mathrm{Al} \%$ \\
\hline AA 5182 & 4.51 & 0.34 & 0.18 & 0.08 & 0.05 & 0.02 & 0.02 & $\begin{array}{c}\text { Rem } \\
.\end{array}$ \\
\hline
\end{tabular}

The mechanical properties of AA 5182 sheet were obtained from tensile test by kim etal[15]. The values of Strain Hardening exponent (n), Strain rate sensivity (m), plastic Anisotropic ratio (R), Yield stress $0.2 \%$ offset (YS) and Strength coefficient (K), which were used in the theoretical determination of FLD, are shown in table (2).

Table (2)Mechanical properties of sheets[15]

\begin{tabular}{|c|c|c|c|c|c|c|}
\hline Material & $\begin{array}{l}\text { Angle } \\
\text { to R.D }\end{array}$ & $\begin{array}{c}\text { Strain } \\
\text { Hardening } \\
\text { exponent }(n)\end{array}$ & $\begin{array}{c}\text { Strain rate } \\
\text { sensivity } \\
\text { (m) }\end{array}$ & $\begin{array}{c}\text { plastic } \\
\text { Anisotropic } \\
\text { ratio }(\mathrm{R})\end{array}$ & $\begin{array}{l}\text { Strength } \\
\text { coefficient } \\
(\mathrm{K})[\mathrm{MPa}]\end{array}$ & $\begin{array}{c}\text { Yield stress } \\
0.2 \% \text { offset(YS) } \\
{[\mathrm{MPa}]}\end{array}$ \\
\hline \multirow{3}{*}{$\begin{array}{l}\text { Polypropylene } \\
\text { core }\end{array}$} & $0^{\circ}$ & 0.13 & 0.05 & --- & 31.3 & 12.4 \\
\hline & $45^{\circ}$ & 0.12 & -- & -- & 30.4 & 12.2 \\
\hline & $90^{\circ}$ & 0.10 & --- & --- & 24.5 & 12.5 \\
\hline \multirow{3}{*}{ AA5182 skin } & $0^{\circ}$ & 0.32 & -0.006 & 1.11 & 647.7 & 133.2 \\
\hline & $45^{\circ}$ & 0.31 & --- & 1.38 & 615 & 132.3 \\
\hline & $90^{\circ}$ & 0.31 & --- & 1.03 & 607 & 128.7 \\
\hline \multirow{3}{*}{ Sandwich sheet } & $0^{\circ}$ & 0.26 & 0.007 & 1.01 & 201.7 & 50.3 \\
\hline & $45^{\circ}$ & 0.27 & --- & 1.33 & 189.9 & 47.0 \\
\hline & $90^{\circ}$ & 0.26 & --- & 1.16 & 188.0 & 46.1 \\
\hline
\end{tabular}


Balod :Theoretical Determination of the formability of (AA5182 / Polypropylene/ ..

Table(3) show the initial defect parameter $(f 0)$, obtained from the surface roughness was measured by a surface roughness analyzer[15].

Table(3)Initial defect parameter of AA5182 skin sheet and sandwich sheets[15]

\begin{tabular}{|l|c|}
\hline Material & Initial defect parameter $\left(\boldsymbol{f}_{\mathbf{0}}\right)$ \\
\hline AA 5182 sheet & 0.985 \\
\hline Sandwich sheets & 0.9975 \\
\hline
\end{tabular}

\section{Theoretical Analysis:}

The theoretical forming limit diagrams presented in this work were calculated using a more general code(M-K analysis and Theory of plasticity) for predicting the forming limits under linear strain paths. The code consists of a main part and several subroutines allowing the implementation of hardening law, yield function. The general structure of theoretical FLD is shown in Fig.(2).

The geometry of neck formation and the element of sheet undergoing plastic deformation are shown in Fig.3. Following the M-K analysis, based on a simplified model with assumed preexisting thickness imperfection in the form of a groove perpendicular to the principal stress directions, The sheet is composed of the nominal area and weak groove area, which are denoted by ' $a$ ' and ' $b$ ', respectively. The initial imperfection factor of the groove, $f 0$, is defined as the thickness ratio $(f 0=\mathrm{t} 0 \mathrm{~b} / \mathrm{t} 0 \mathrm{a})$; where $(\mathrm{t})$ denotes the thickness and subscript $(0)$ denotes the initial state. A biaxial stress state is imposed on the nominal area and causes the development of strain increments in both the nominal (a) and the weak area (b).

In theoretical solution of forming limit diagram for sandwich sheet the two anisotropic yield criterion Hosford and Barlat-lian were used.

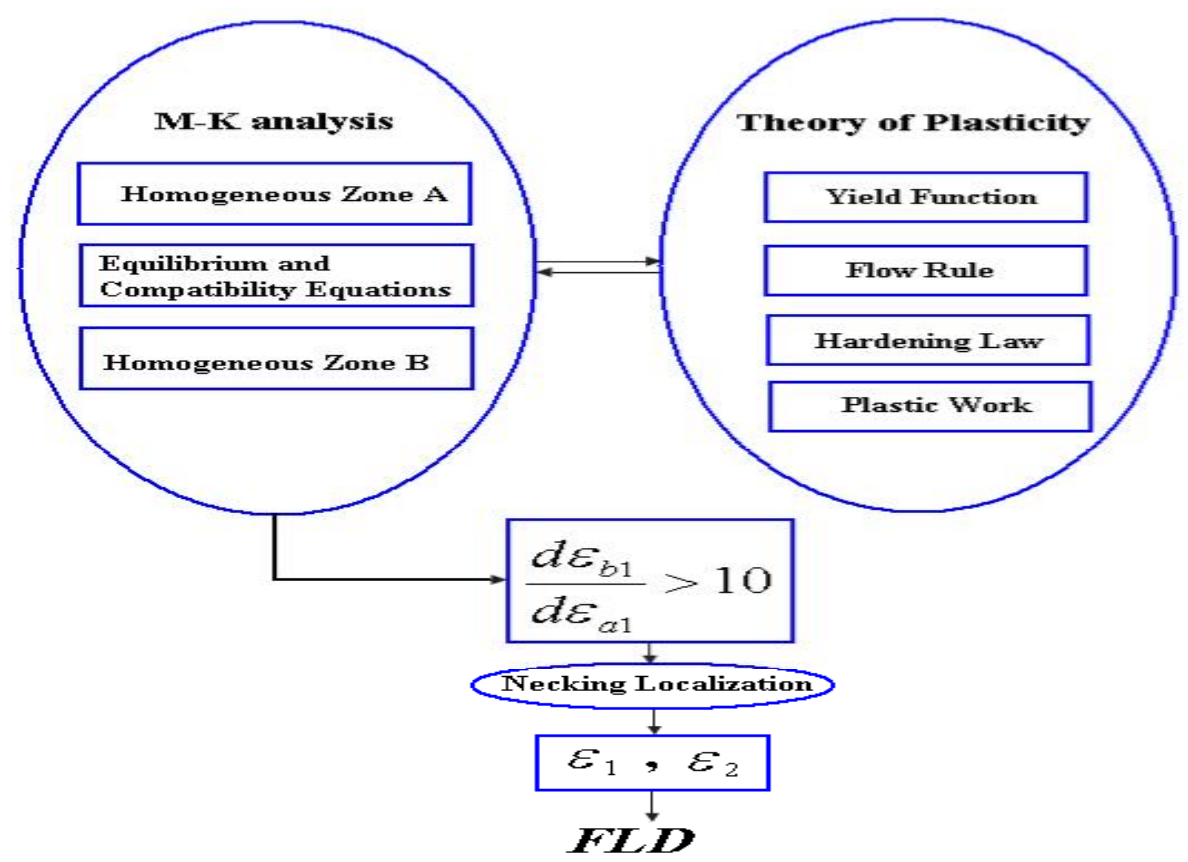

Fig.2 General structure of theoretical FLD 
3.1 Hosford anisotropic yield criterion with M-K analysis:

The yield criterion proposed by Hosford[8] was used in the calculation in the plane stress state, this criterion is obtained as follows :

$\left(\sigma^{\prime}\right)^{a}=\frac{1}{\left(R^{\prime}+1\right)}\left[\left(\sigma_{1}\right)^{a}+\left(\sigma_{2}\right)^{a}+R^{\prime}\left(\sigma_{1}-\sigma_{2}\right)^{a}\right]$

using $\mathrm{a}=8$

from eq.(1)

$\varphi=\frac{\sigma_{1}}{\sigma^{\prime}}=\left[\frac{\left(R^{\prime}+1\right)}{1+(\alpha)^{a}+R^{\prime}(1-\alpha)^{a}}\right]^{\left(\frac{1}{a}\right)}$

The behavior of material can be represented in the form of Power law

$\sigma^{\prime}=K \varepsilon^{\prime n} \dot{\varepsilon}^{\prime m}$

The ratio of the principal stress and strain are defined as follows:

$\alpha=\frac{\sigma_{2}}{\sigma_{1}} \quad, \rho=\frac{\varepsilon_{2}}{\varepsilon_{1}}=\frac{d \varepsilon_{2}}{d \varepsilon_{1}}$.

The associated flow rule is expressed by

$d \varepsilon_{i j}=d \lambda \frac{\partial \sigma^{\prime}}{\partial \sigma_{i j}}$

and

$d \varepsilon_{1}=\frac{d \varepsilon^{\prime} \varphi^{a-1}}{\left(R^{\prime}+1\right)}\left[1+R^{\prime}(1-\alpha)^{a-1}\right]$.

$d \varepsilon_{2}=\frac{d \varepsilon^{\prime} \varphi^{a-1}}{\left(R^{\prime}+1\right)}\left[(\alpha)^{a-1}-R^{\prime}(1-\alpha)^{a-1}\right]$

using condition of constant volume in plastic deformation

$d \varepsilon_{1}+d \varepsilon_{2}+d \varepsilon_{3}=0$

from eq.(8)

$d \varepsilon_{3}=-\frac{d \varepsilon^{\prime} \varphi^{a-1}}{\left(R^{\prime}+1\right)}\left[1+(\alpha)^{a-1}\right]$

then, by applying the principle of equivalence of plastic work $\sigma^{\prime} d \varepsilon^{\prime}=\sigma_{1} d \varepsilon_{1}+\sigma_{2} d \varepsilon_{2}$

the compatibility condition is given by 
$d \varepsilon_{2 a}=d \varepsilon_{2}$

from Marciniak-Kuczynski analysis [3].

$f=\frac{t_{b}}{t_{a}}$

$f=f_{o} \exp \left(\varepsilon_{3 b}-\varepsilon_{3 a}\right) \ldots \ldots \ldots$

the equilibrium condition requires that the applied load remains constant along the specimen ;

$F_{1 a}=F_{1 b}$

from eq.(3),(14)

$\varphi_{a}\left(\varepsilon_{a}^{\prime}+d \varepsilon_{a}^{\prime}\right)^{n} \dot{\varepsilon}_{a}^{\prime m}=f \varphi_{b}\left(\varepsilon_{b}^{\prime}+d \varepsilon_{b}^{\prime}\right)^{n} \dot{\varepsilon}_{b}^{\prime m}$

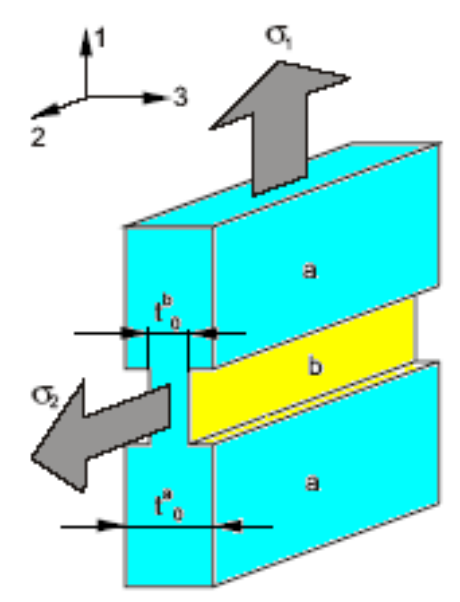

Fig.(3) Marciniak-Kuczynski analysis

Equilibrium equation (15), is an equation that can be found and solved numerically. Imposing a loading path ( $\rho$ a), a finite increment of strain is also imposed in region (a), and numerical computation is performed by using computer program (Fortran power Station) to determine the limit strain of a strain path in the FLD , and the limit strain is determined when [(d $\varepsilon b 1 / \mathrm{d} \varepsilon a 1)>10]$ in the range of strain ratios from (-0.5 to 1.0$)$.

\subsection{Barlat-Lian anisotropic yield criterion with M-K analysis:}

The yield criterion proposed by barlat-lian[16] was used in the calculation in the plane stress state , this criterion is obtained as follows : 


$$
\begin{aligned}
& \sigma^{\prime}=\left[\frac{1}{2}\left(A\left(K_{1}-K_{2}\right)^{a}+A\left(K_{1}+K_{2}\right)^{a}+(2-A)\left(2 K_{2}\right)^{a}\right)^{\frac{1}{a}}\right. \\
& K_{1}=\frac{\sigma_{1}+h \sigma_{2}}{2} \\
& K_{2}=\frac{\sigma_{1}-h \sigma_{2}}{2} \\
& h=\sqrt{\frac{R_{0}\left(1+R_{90}\right)}{R_{90}\left(1+R_{0}\right)}}, \quad . c=\sqrt{\frac{R_{0} R_{90}}{\left(1+R_{0}\right)\left(1+R_{90}\right)}}, \quad c=2-A .
\end{aligned}
$$

using $\mathrm{a}=8$

from Eq.(16)

$\varphi=\frac{\sigma_{1}}{\sigma^{\prime}}=\left[\frac{1}{2}\left(A\left(\frac{1+h \alpha}{2}-\frac{1-h \alpha}{2}\right)^{a}+A\left(\frac{1+h \alpha}{2}+\frac{1-h \alpha}{2}\right)^{a}+(2-A)\left(2\left(\frac{1-h \alpha}{2}\right)\right)^{a}\right)\right]^{\left(^{-\frac{1}{a}}\right)}$

The behavior of material can be represented in the form of Power law $\sigma^{\prime}=K \varepsilon^{\prime n} \dot{\varepsilon}^{\prime m}$

The ratio of the principal stress and strain are defined as follows:

$\alpha=\frac{\sigma_{2}}{\sigma_{1}} \quad, \rho=\frac{\varepsilon_{2}}{\varepsilon_{1}}=\frac{d \varepsilon_{2}}{d \varepsilon_{1}}$

The associated flow rule is expressed by

$d \varepsilon_{i j}=d \lambda \frac{\partial \sigma^{\prime}}{\partial \sigma_{i j}}$.

and

$$
\begin{aligned}
& d \varepsilon_{1}=\frac{d \varepsilon^{\prime} \varphi^{a-1}}{2}\left[A\left(\frac{1+h \alpha}{2}+\frac{1-h \alpha}{2}\right)^{a-1}+c(1-h \alpha)^{a-1}\right] \ldots \\
& d \varepsilon_{2}=\frac{d \varepsilon^{\prime} \varphi^{a-1}}{2}\left[A h\left(\frac{1+h \alpha}{2}+\frac{1-h \alpha}{2}\right)^{a-1}-\operatorname{ch}(1-h \alpha)^{a-1}\right]
\end{aligned}
$$

using condition of constant volume in plastic deformation $d \varepsilon_{1}+d \varepsilon_{2}+d \varepsilon_{3}=0$ 
from eq.(26)

$d \varepsilon_{3}=-\frac{d \varepsilon^{\prime} \varphi^{a-1}}{2}\left[A\left(\frac{1+h \alpha}{2}+\frac{1-h \alpha}{2}\right)^{(a-1)}+A h\left(\frac{1+h \alpha}{2}-\frac{1-h \alpha}{2}\right)^{(a-1)}+c(1-h \alpha)^{a-1}(1-h)\right]$

then, by applying the principle of equivalence of plastic work

$\sigma^{\prime} d \varepsilon^{\prime}=\sigma_{1} d \varepsilon_{1}+\sigma_{2} d \varepsilon_{2}$

the compatibility condition is given by

$d \varepsilon_{2 a}=d \varepsilon_{2 b}$

from Marciniak-Kuczynski analysis [3].

$f=\frac{t_{b}}{t_{a}}$

$f=f_{o} \exp \left(\varepsilon_{3 b}-\varepsilon_{3 a}\right)$

the equilibrium condition requires that the applied load remains constant along the specimen ; therefore

$F_{1 a}=F_{1 b}$

from eq.(21),(32)

$\varphi_{a}\left(\varepsilon_{a}^{\prime}+d \varepsilon_{a}^{\prime}\right)^{n} \dot{\varepsilon}_{a}^{\prime m}=f \varphi_{b}\left(\varepsilon_{b}^{\prime}+d \varepsilon_{b}^{\prime}\right)^{n} \dot{\varepsilon}_{b}^{\prime m}$

Equilibrium equation (33), is an equation that can be found and solved numerically. Imposing a loading path ( $\mathrm{pa})$, a finite increment of strain is also imposed in region (a), and by numerical computation is performed by using computer program (Fortran power Station) to determine the limit strain of a strain path in the FLD , and the limit strain is determined when $[(\mathrm{d} \varepsilon b 1 / \mathrm{d} \varepsilon a 1)>10]$ in the range of strain ratios from (-0.5 to 1.0$)$.

\subsection{Determining the forming limit stress diagram (FLSD):}

\subsubsection{Theoretical determination of forming limit stress diagram (FLSD):}

In the theoretical determination the same step of theoretical forming limit strain diagram are used but using equation to continue determining the limit stress on FLSD[17].

$\sigma_{1}=\sigma^{\prime}\left(\varepsilon^{\prime}\right) \times \varphi(\alpha)$

to determined minor stress using the stress ratio:

$\alpha=\frac{\sigma_{2}}{\sigma_{1}}$

3.3.2Calculation of forming limit stress diagram (FLSD) based on experimental Strain data[15] :

Based on the experimental forming limit strains and using the plasticity theory, the forming limit stresses are computed[17]. In this paper we can use major true strain and strain ratio(Eq.36) from forming limit strain diagram for sandwich sheet and AA5182 sheet skin. 
$\rho=\frac{\varepsilon_{2}}{\varepsilon_{1}}$

By using plasticity theory that presented by Barlat-lian yield function(Eq.37), plastic work (Eq.38) and hardening law (power law) (Eq.39).

$\sigma^{\prime}=\left[\frac{1}{2}\left(A\left(K_{1}-K_{2}\right)^{a}+A\left(K_{1}+K_{2}\right)^{a}+(2-A)\left(2 K_{2}\right)^{a}\right)\right]^{\frac{1}{a}}$

$\sigma^{\prime} d \varepsilon^{\prime}=\sigma_{1} d \varepsilon_{1}+\sigma_{2} d \varepsilon_{2}$

and by hardening law (power law)

$\sigma^{\prime}=K \varepsilon^{\prime n}$

and the stress ratio is :

$\alpha=\frac{\sigma_{2}}{\sigma_{1}}$

For cases with non shear stress in a coordinate system aligned with the axes of anisotropy, the major true stress can be expressed as follows:

$\sigma_{1}=\sigma^{\prime}\left(\varepsilon^{\prime}\right) \times \varphi(\alpha)$

where $\sigma^{\prime}\left(\varepsilon^{\prime}\right)$ represents the effective stress computed through the hardening law, and $\varphi(\alpha)$ function of material parameters are derived from the applied yield criteria. the effective strain is obtained for Barlat-lian yield criteria through the corresponding plastic strain in this paper, and the minor true stress is calculated by using the stress ratio(Eq.(40)).

The above equations show that the experimental forming limit stress diagram depends on the shape of the yield surface as well as the hardening law used to describe the work hardening material behavior[17].

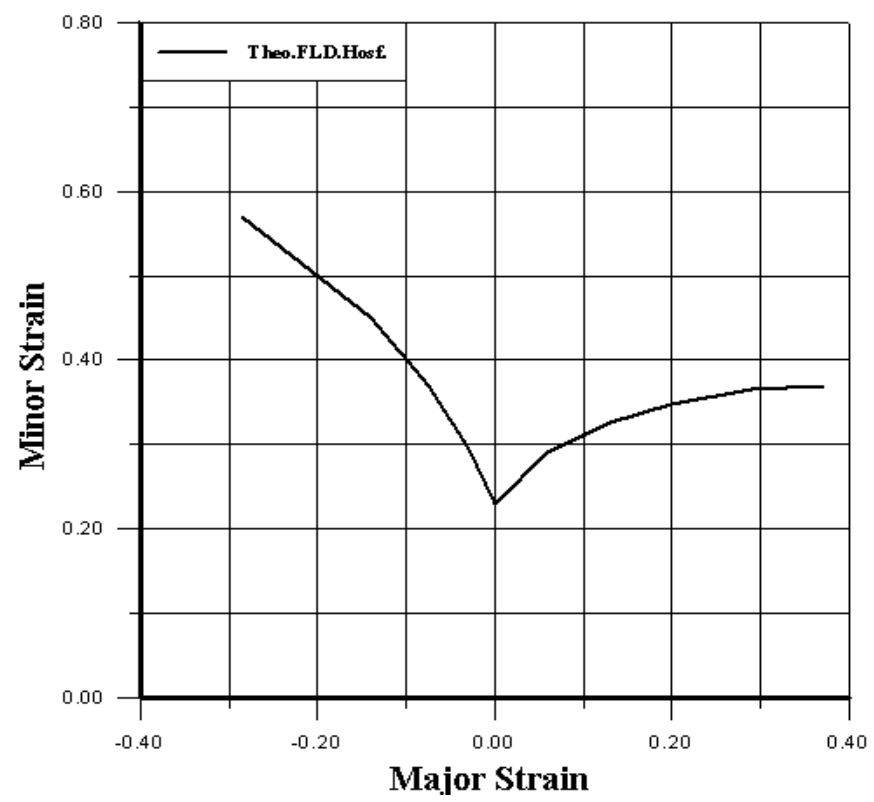

Fig.(4) Theo. FLD of sandwich sheets (AA/PP/AA) using Hosford yield criterion 


\section{Results and Discussion}

Figure(4)shows the theoretical forming limit curve of (AA/PP/AA)sandwich sheets determined using Hosford yield criterion with high exponent $(a=8)$. Figure(5)shows the theoretical forming limit curve of $(\mathrm{AA} / \mathrm{PP} / \mathrm{AA})$ sandwich sheets using Barlat-lian yield criterion with high exponent $(\mathrm{a}=8)$.

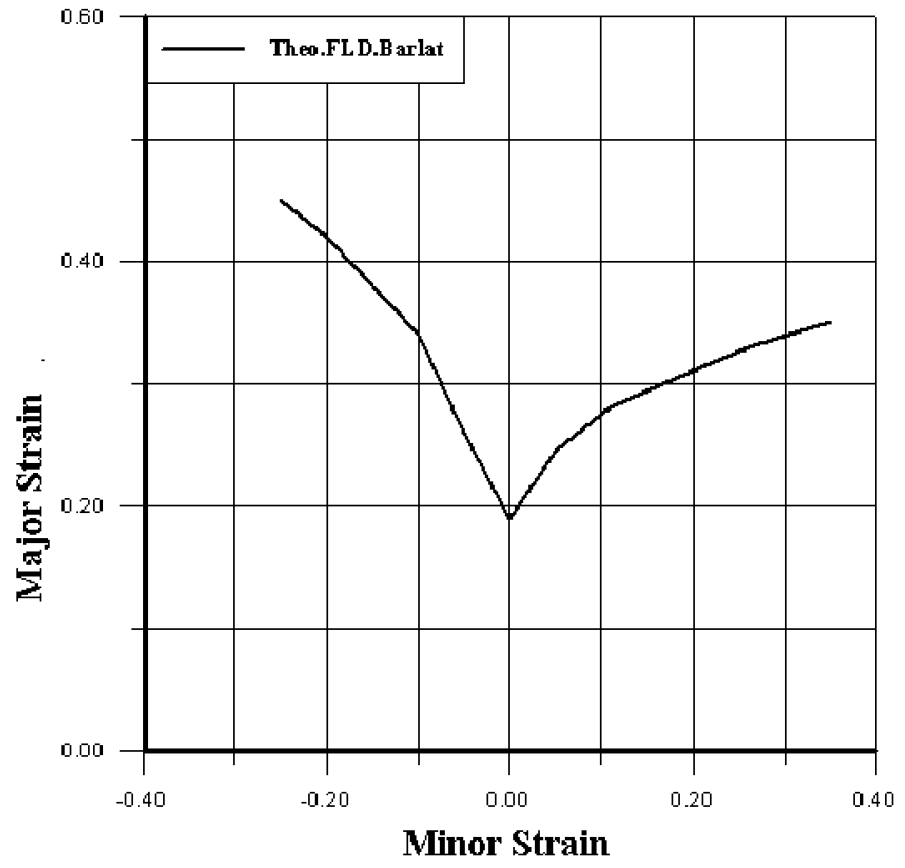

Fig.(5) Theo. FLD of sandwich sheets (AA/PP/AA) using Barlat-Lian yield criterion



Fig.(6) comparison between the theoretical and experimental FLDs of Sandwich sheets 


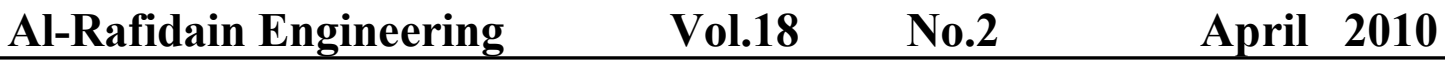

Figure(6) shows the comparison between the theoretical (determined by both methods)and experimental forming limit(by Kim[15]) curves of (AA/PP/A A)sandwich sheets, It can be seen from comparison that the theoretical curve using (Barlat -Lian yield criterion) is the closer to the experimental curve.

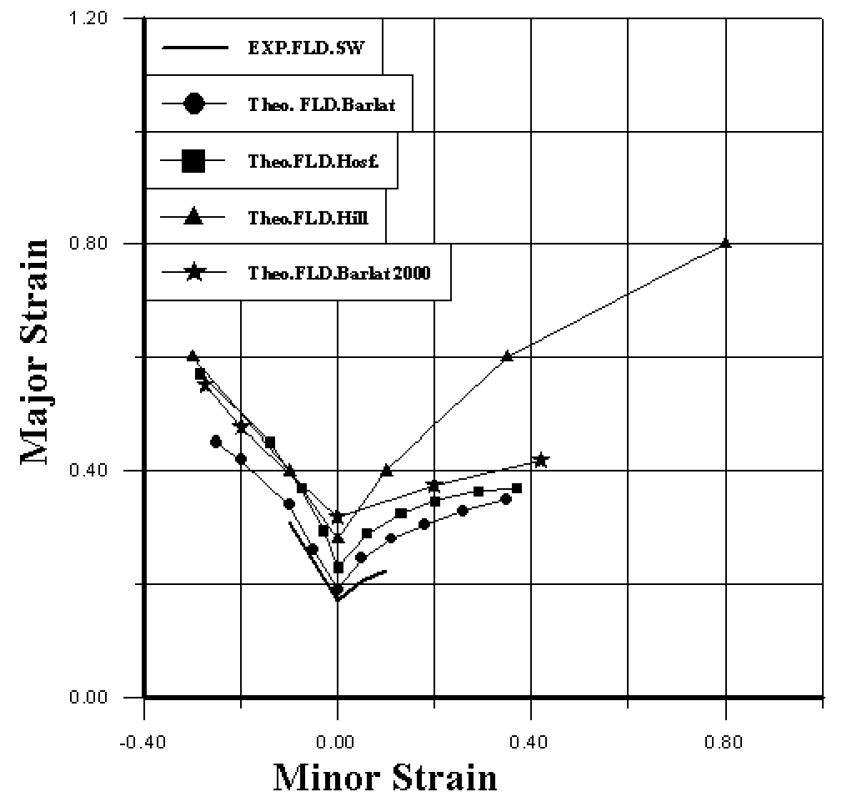

Fig.(7) comparison between the theoretical forming limit curves(Barlat-Lian\&Hosford) and theoretical forming limit curves of Kim (Barlat 2000\&Hill 1948)[15] and experimental forming limit curves of (AA/PP/AA)sandwich sheets

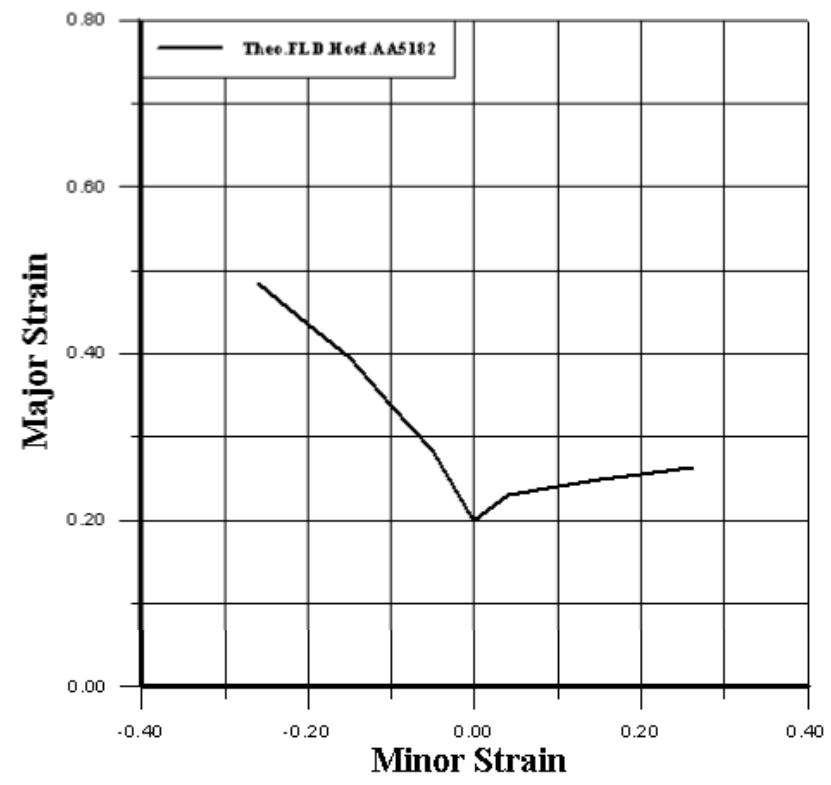

Fig.(8) Theoretical FLD of AA5182 sheet using Hosford yield criterion 
Figure(7) shows the comparison between the theoretical forming limit curves(Barlat-Lian \& Hosford) and theoretical forming limit curves of Kim (Barlat 2000\&Hill 1948)[15] and experimental forming limit curve of (AA/PP /AA)sandwich sheets, It can be seen from comparison that the theoretical curve using (Barlat -Lian yield criterion) is the closer to the experimental curve.

Figure(8)shows the theoretical forming limit curve of the $0.2 \mathrm{~mm}$ thickness(AA 5182)skin sheet using Hosford yield criterion with high exponent $(a=8)$. Figure $(9)$ shows the theoretical forming limit curve of $0.2 \mathrm{~mm}$ thickness (AA5182)skin sheet using Barlat-lian yield criterion with high exponent $(a=8)$.

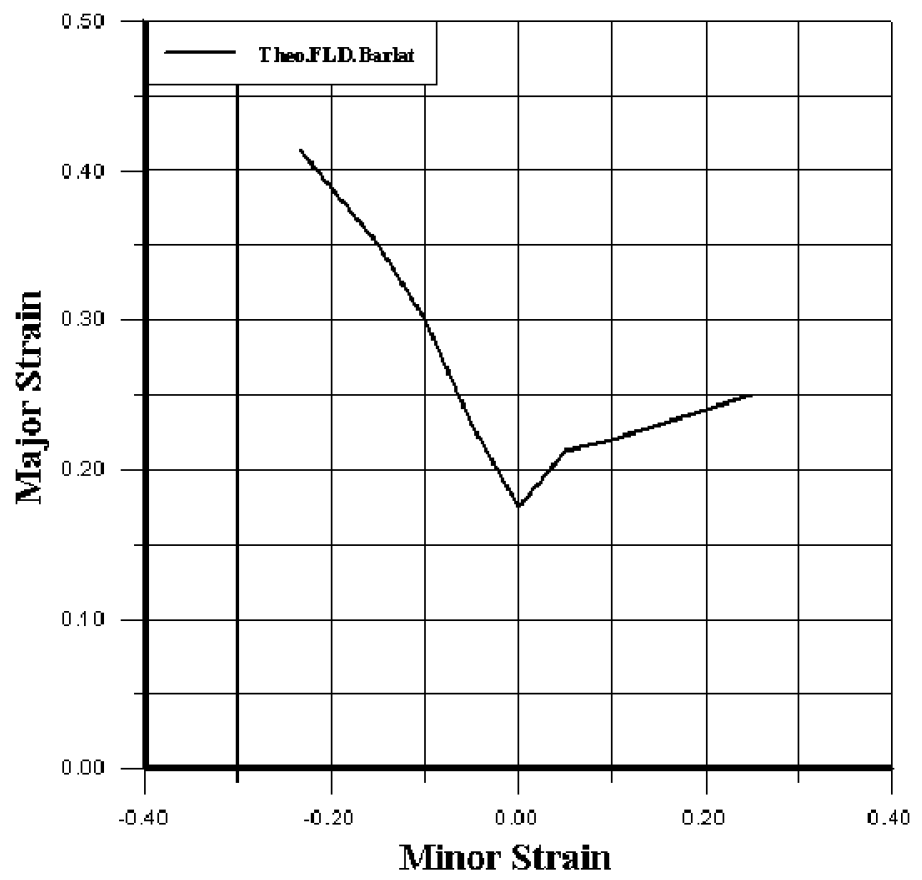

Fig.(9) Theoretical FLD of AA5182 sheet using Barlat-Lian yield criterion

Figure(10) shows the comparison between the theoretical and experimental forming limit(by Kim[15]) curves of the $0.2 \mathrm{~mm}$ thickness of AA5182 skin sheet, It can be seen from comparison that the theoretical curve using (Barlat -Lian yield criterion) is the closer to the experimental curve.

Figure(11) shows the comparison between the theoretical forming limit curves(BarlatLian\&Hosford) and theoretical forming limit curves of Kim (Barlat 2000\&Hill 1948)[15] and experimental forming limit curve(by Kim[15]) for $0.2 \mathrm{~mm}$ thickness AA5182 skin sheet, It can be seen from comparison that the theoretical curve using (Barlat -Lian yield criterion) is closer to the experimental curve, and show very high difference between the theoretical curve using(Hill 1948 yield criterion) and the experimental curve especial in right of curve. 


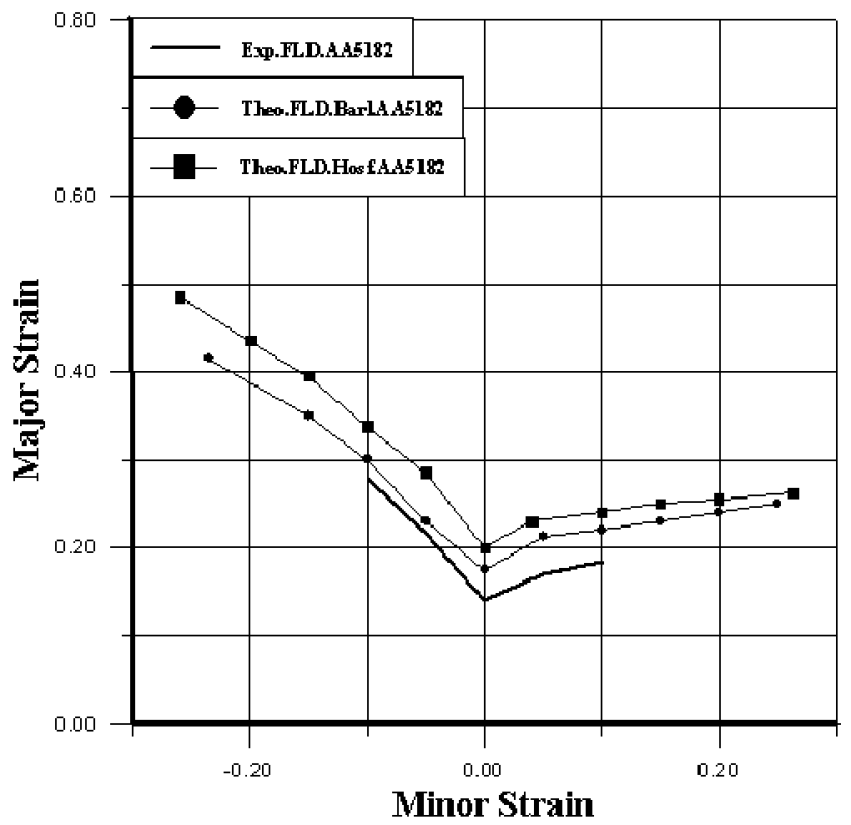

Fig.(10) Comparison between the theoretical and experimental FLDs of AA5182 sheet

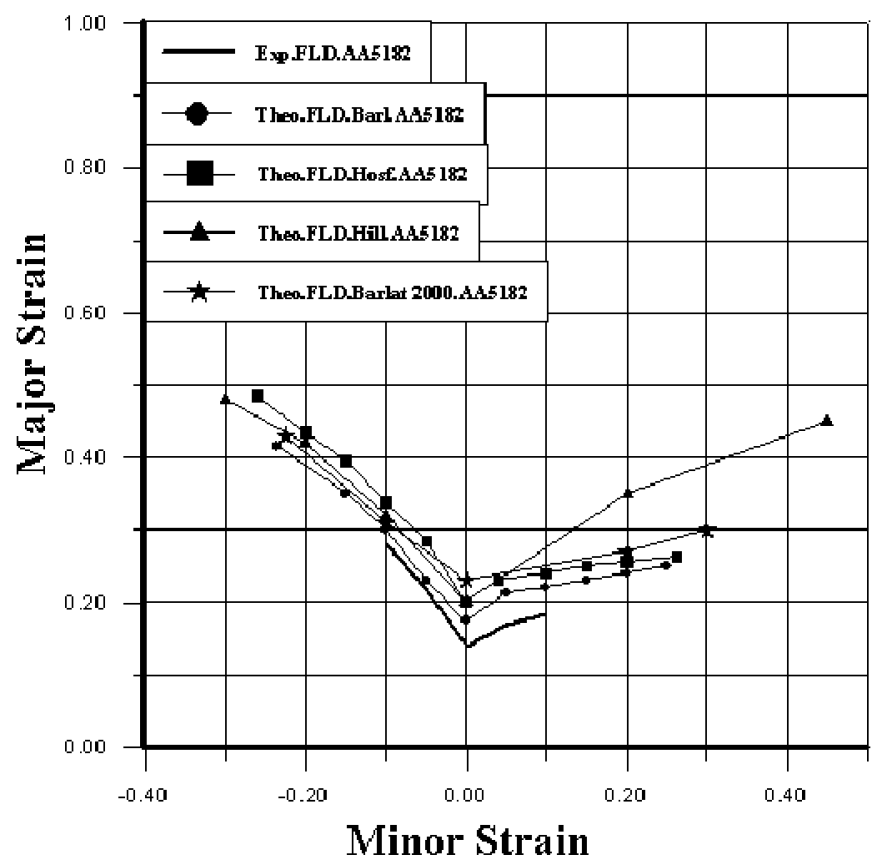

Fig.(11) Comparison between the theoretical forming limit curves(Barlat-Lian\&Hosford) and theoretical forming limit curves of Kim (Barlat 2000\&Hill 1948)[15] and experimental forming limit curve of the $0.2 \mathrm{~mm}$ thickness AA5182 skin sheet 
Balod :Theoretical Determination of the formability of (AA5182 / Polypropylene/ ..

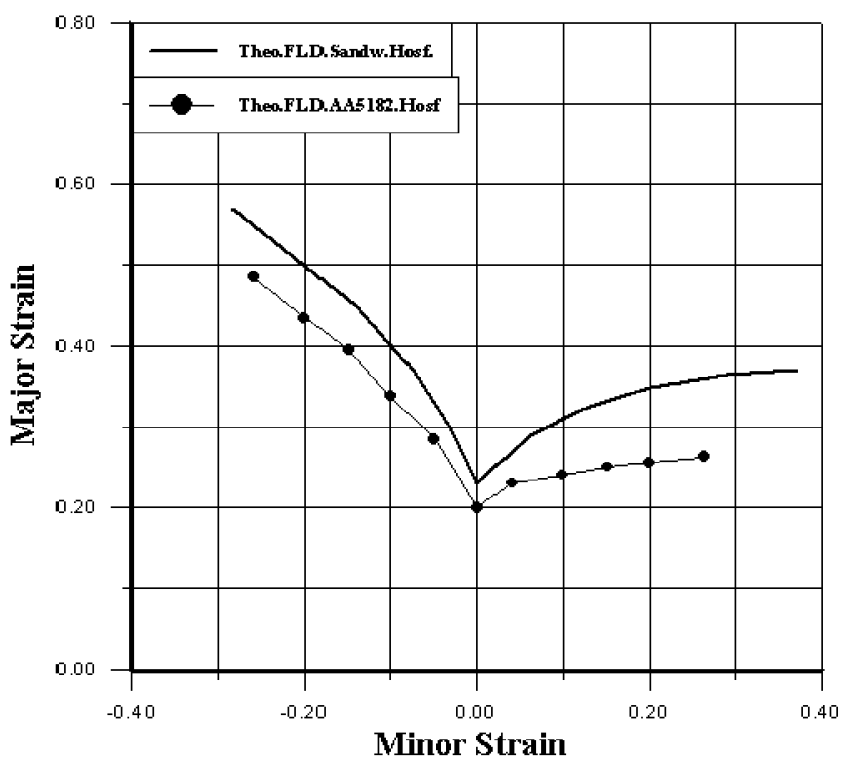

Fig.(12) Comparison between the theoretical FLD of sandwich and AA5182 sheets using Hosford yield criterion

Figure(12) shows the comparison between the theoretical forming limit curves of sandwich (AA/PP/AA) and AA5182 sheets using Hosford yield criterion, It can be seen from comparison that the formability of sandwich sheets is higher than $0.2 \mathrm{~mm}$ thickness of AA5182 skin sheet, because the strain rate sensitivity and initial defect parameters of the sandwich sheet are higher than those of the AA5182 skin sheet.

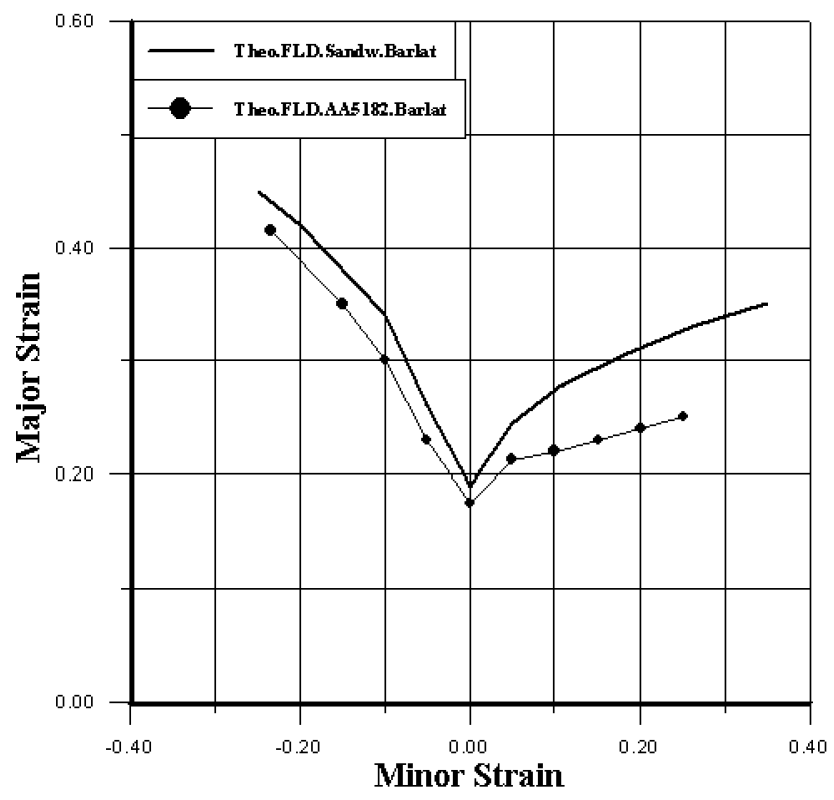

Fig.(13) Comparison between the theoretical FLD of sandwich and AA5182 sheets using Barlat-Lian yield criterion 


\section{Al-Rafidain Engineering $\quad$ Vol.18 $\quad$ No.2 $\quad$ April 2010}

Figure(13) shows the comparison between the theoretical forming limit curves of sandwich (AA/PP /AA) and AA5182 sheets using Barlat-lian yield criterion, It can be seen from comparison that the formability of sandwich sheets is higher than $0.2 \mathrm{~mm}$ thickness AA5182 skin. because the strain rate sensitivity (polypropylene core) and initial (thickness $=1.2 \mathrm{~mm}$ ) defect parameters of the sandwich sheet are higher than those of the AA5182 skin sheet

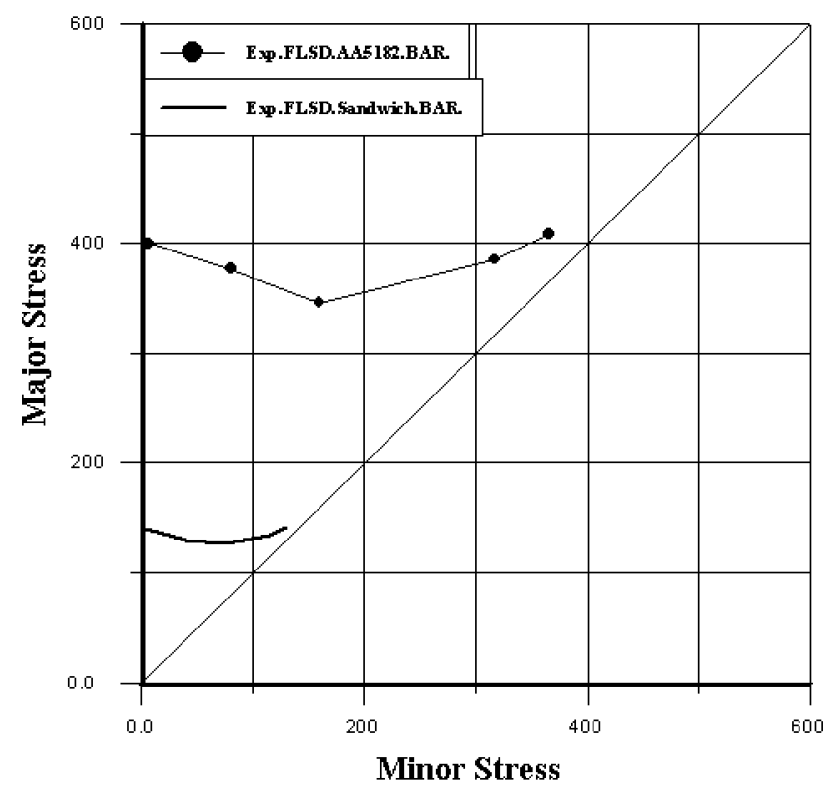

Fig.(14) Comparison between the experimental FLSDs of sandwich and AA5182 sheets using Barlat-Lian yield criterion

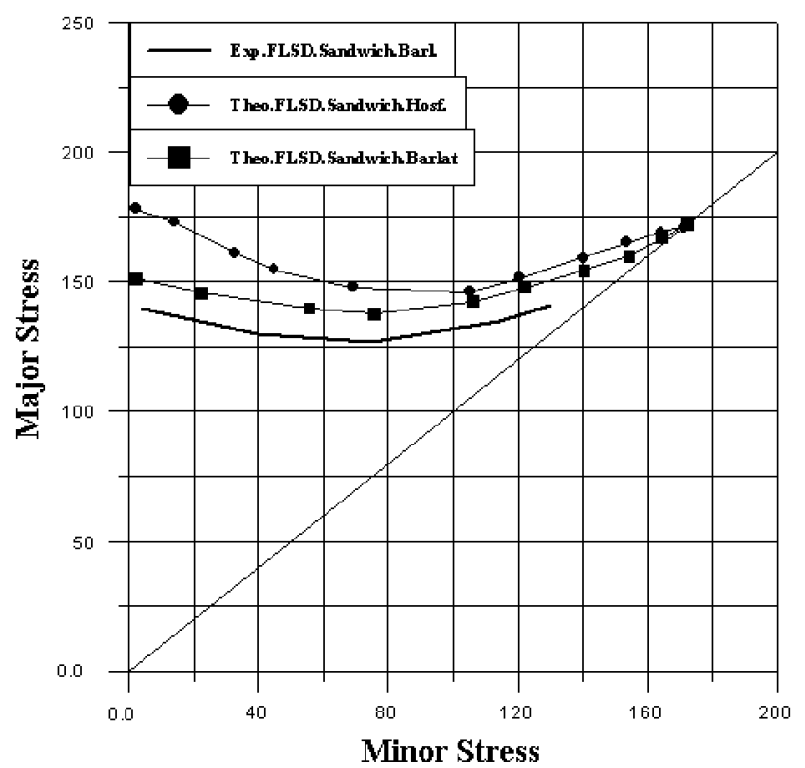

Fig.(15) comparison between the theoretical and experimental FLSDs of Sandwich sheets 
Balod :Theoretical Determination of the formability of (AA5182 / Polypropylene/ ..

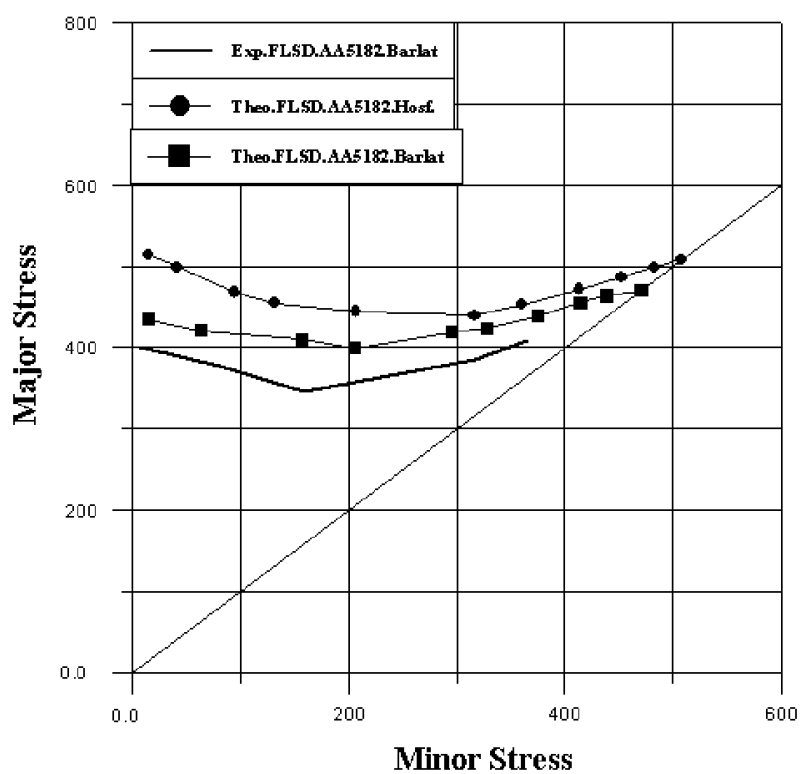

Fig.(16) comparison between the theoretical and experimental FLSDs of skin AA5182 sheet

Figure(14) shows the comparison between the experimental forming limit stress curves of sandwich (AA/PP/AA) and AA5182 sheets using Barlat-lian yield criterion, It can be seen from comparison that the limit stress of $0.2 \mathrm{~mm}$ thickness AA5182 skin sheet is higher than sandwich sheets, it is observed that the level of the FLSD depends on the selection of Strength coefficient , and the strength coefficient of $0.2 \mathrm{~mm}$ thickness AA5182 skin sheet is higher than sandwich sheets. When the Strength coefficient increases the predicted forming limit stress curve is also increased

Figure(15) shows the comparison between the theoretical and experimental forming limit stress curves of (AA/PP/AA)sandwich sheets, It can be seen from comparison that the theoretical curve using Barlat yield criterion is closer to the experimental curve.

Figure(16) shows the comparison between the theoretical and experimental forming limit stress curves of $0.2 \mathrm{~mm}$ thickness AA5182 skin sheet, It can be seen from comparison that the theoretical curve using Barlat yield criterion is closer to the experimental curve.

\section{5-Conclusions:}

The forming limit diagram of the $1.2 \mathrm{~mm}$ thickness AA/PP/AA sandwich sheet and the $1.2 \mathrm{~mm}$ thickness AA5182 skin was determined based on the modified $\mathrm{M}-\mathrm{K}$ analysis employing Hosford and Barlat-lian yield functions. These values were then compared to the experimentally measured values by (Kim 2003[15]), the following conclusions can be obtained .

1- the Barlat-lian yield criterion is the best anisotropic yield criterion for sandwich sheets in theoretical determination of forming limit diagram and experimental -theoretical determination of forming limit stress diagram.

2- The theoretical FLD of sandwich sheets is higher than the FLD of Al-Alloy (AA5182)skin $(0.2 \mathrm{~mm}$ thickness)alone.

3- The limit stress in FLSD of $0.2 \mathrm{t}$ AA51 82 skin sheet is higher than sandwich sheets. 


\section{Al-Rafidain Engineering $\quad$ Vol.18 $\quad$ No.2 $\quad$ April 2010}

\section{6-Reference:}

1-Semiatin S.L. and Piehler H.R.( 1979), "Forming limits of sandwich sheet materials",Vol.10A.

2-17. Hill,R.,"A theory of the yielding and plastic flow of anisotropic materials", Proceedings of Royal society of London: A193:281-97,1948.

3.Marciniak, Z. and Kuczynski, K. (1967), Limits Strains in The Processes of Stretch-Forming Sheet Metal, Int. J. Mech. Sci .Vol. 9, pp. 609-620 .

4 Painter M.J. and Pearce R., (1974) Instability and Fracture in Sheet Metal, J. Phys. D: Appl. Phys., Vol. 7, pp. 992-1002.

5. Sowerby R. and Duncan, D.L. (1971), Failure in Sheet Metal in Biaxial Tension, Int. J. Mech. Sci. vol. 13, pp. 217-229.

6. Hill, R. (1979), Theoretical Plasticity of Textured Aggregates, Math. Proc. Camb. Phil.Soc. vol. 55, pp.179-191.

7. Parmar, A. and Mellor, P.B. (1978), Predictions of Limit Strains in Sheet Metal Using A More General Yield Criterion, Int. J. Mech. Sci., vol. 20, pp. 385-391.

8. Hosford.W.F, On yield loci of anisotropic cubic metals. Proc. 7th North American Metalworking Conference, S.M.E., Dearborn, MI, USA, p. 191 (1979).

9. Graf, A. and Hosford, W.F. (1990), Calculations of forming limit diagrams. Metall. Trans. vol. 21A, pp. 87-96 .

10. Padwal, S.B. and Chaturvedi, R.C. (1992), Prediction of Forming Limits Using Hosford's Modified Yield Criterion, Int. J. Mech. Sci. vol. 34, No. 7, pp. 541-547 .

11. Hosford W.F. (1985)," Comments on Anisotropic Yield Criteria”, Int. J. Mech. Sci., Vol. 27, No. 7/8, pp. 423-427

12. Friedman.P.A., Pan.J.," Effect of plastic anisotropic and yield criteria on prediction of forming limit curves ",International Journal of Mechanical Sciences 42(2000)29-48.

13. Dariani.B.M. and Azodi.H.D. ,'Finding the optimum Hill index in the determination of the forming limit diagram", Journal of Engineering Manufacture .Vol.217.pp.1677-1683 (2003).

14. K.J. Kim, K.S. Shin, in: Proceedings of the Fifth Next Generation Vehicle Workshop, KATECH, Korea, 1997, p. 639.

15. Kim,K.J;Choi,S.H., Formability of AA5182/polypropylene/AA5182 Sandwich sheets,

16.Barlat F. and Lian, J. (1989). Plastic Behavior and Stretchability of Sheet Metals. Part I: A Journal of Materials Processing Technology 139 (2003) , P.1-7.

Yield Function for Orthotropic Sheets under Plane Stress Conditions. Int. J. of Plast. vol. 5, pp. 51-66.

17. Butuc MC, Barata da Rocha A, Gracio JJ. "An experimental and theoretical analysis on the application of stress-based forming limit criterion", International Journal of Mechanical Sciences,vol.48, pp. 414-429,(2006). 